\title{
A Single Amino Acid Change In Histone Methyltransferase CURLY LEAF Results In Premature Bolting In Chinese Cabbage (Brassica Rapa L. Ssp. Pekinensis)
}

\section{Chong Tan}

Shenyang Agricultural University

Jie Ren

Shenyang Agricultural University

\section{Lin Wang}

Shenyang Agricultural University

\section{Xueling Ye}

Shenyang Agricultural University

\section{Wei Fu}

Shenyang Agricultural University

\section{Jiamei Zhang}

Shenyang Agricultural University

Meng Qi

Shenyang Agricultural University

\section{Hui Feng}

Shenyang Agricultural University

Zhiyong Liu ( $\nabla$ liuzhiyong99@syau.edu.cn )

Shenyang Agricultural University https://orcid.org/0000-0002-7366-6511

\section{Research article}

Keywords: Chinese cabbage, Premature bolting, MutMap, CURLY LEAF, EMS mutagenesis

Posted Date: January 16th, 2021

DOI: https://doi.org/10.21203/rs.3.rs-143818/v1

License: (a) (i) This work is licensed under a Creative Commons Attribution 4.0 International License. Read Full License

Version of Record: A version of this preprint was published at BMC Plant Biology on August 13th, 2021. See the published version at https://doi.org/10.1186/s12870-021-03153-9. 


\section{Abstract}

Background: Flowering is an important inflection point in the transformation from vegetative to reproductive growth, and premature bolting severely decreases crop yield and quality.

Results: In this study, a stable early-bolting mutant, ebm3, was identified in an ethyl methanesulfonate (EMS)mutagenized population of a Chinese cabbage doubled haploid (DH) line 'FT'. Compared with 'FT', ebm3 showed early bolting under natural cultivation in autumn, and curled leaves. Genetic analysis showed that the early-bolting phenotype was controlled by a single recessive nuclear gene. Modified MutMap and genotyping analyses revealed that Brebm3 (BraA04g017190.3C), encoding the histone methyltransferase CURLY LEAF (CLF), was the causal gene of the emb3. A C to T base substitution in the 14th exon of Brebm3 resulted in an amino acid change ( $\mathrm{S}$ to $\mathrm{F}$ ) and the early-bolting phenotype of emb3. The mutation occurred in the SET domain (Suppressor of protein-effect variegation 3-9, Enhancer-of-zeste, Trithorax), which catalyzes site- and state-specific lysine methylation in histones. Tissue-specific expression analysis showed that $\mathrm{Brebm} 3$ was highly expressed in the flower and bud. Promoter activity assay confirmed that Brebm3 promoter was active in inflorescences. Subcellular localization analysis revealed that Brebm3 localized in the nucleus.

Transcriptomic studies supported that Brebm3 mutation might repress H3K27me3 deposition and activate expression of the AGAMOUS $(A G)$ and AGAMOUS-like $(A G L)$ loci, resulting in early flowering.

Conclusions: Our study revealed that an EMS-induced early-bolting mutant ebm3 in Chinese cabbage was caused by a nonsynonymous mutation in BraA04g017190.3C, encoding the histone methyltransferase CLF.These results improve our knowledge of the genetic and genomic resources of bolting and flowering, and may be beneficial to the genetic improvement of Chinese cabbage.

\section{Background}

Flowering is a crucial developmental process that marks the transition from vegetative to reproductive growth, and is essential for propagation. The timing of floral induction is determined by the interaction of environmental and endogenous cues, ensuring that flowering occurs under the conditions the most likely to maximize offspring quantity and quality $[1,2]$. One goal of plant breeding is to improve plant adaptability to climate changes and new environment by controlling flowering time, to ultimately increase crop yield and quality. An enhanced understanding of the flowering regulatory network is of great value for crop genetic selection and improvement.

The genetic control of flowering time, including its interwoven network, has been extensively studied in the plant model species Arabidopsis thaliana. In this species, six major genetic pathways controlling flowering time, i.e., photoperiod, vernalization, autonomous, gibberellin, ambient temperature, and age, have been described [3]. In the floral induction phase, these pathways converge on floral integrator genes to control flowering time, thereby activating the downstream meristem identity genes. In A. thaliana, FLOWERING T(FT) and SUPPRESSOR OF OVEREXPRESSION OF CONSTANS 1/ AGAMOUS-LIKE 20 (SOC1/AGL20) are the two key floral integrator genes [4]. FT, which belongs to the phosphatidylethanolamine-binding protein (PEBP) family, has two homologs, namely TWIN SISTER OF FT (TSF) and TERMINAL FLOWER 1 (TFL1). FT is produced in the leaves and is transported via the phloem to the shoot apical meristem (SAM), where it 
interacts with FLOWERING LOCUS D (FD) to induce SOC1 and the floral meristem identify genes APETALA 1 $(A P 1)$ and CAULIFLOWER $(C A L)[5]$.

The photoperiod and vernalization pathways control flowering in response to seasonal changes in day length and temperature [5]. In the photoperiod pathway, CONSTANS $(C O)$ is the main positive regulator of $F T / T S F$. CYCLING DOF FACTORs (CDFs) are transcriptional repressors of CO. FLAVIN-BINDING KELCH REPEAT F-BOX 1 (FKF1) and GIGANTEA (GI) form a stable complex that releases repression of $C O$ by inducing degradation of CDF1 [6]. At the posttranscriptional level, CONSTITUTIVE PHOTOMORPHOGENIC 1 (COP1) and SUPPRESSOR OF PHYTOCHROME A (SPA1) form a ubiquitin ligase complex that facilitates CO degradation in the dark [5]. In the vernalization pathway, FLOWERING LOCUS C (FLC), which encodes a MADS-box transcription factor, acts as a central floral repressor by directly repressing the transcription of the floral promoting genes FT, SOC1, and SQUAMOSA PROMOTER-BINDNG PROTEIN-LIKE 15 (SPL 15) [7]. FRIGIDA $(F R I)$, which encodes a coiled-coil protein, positively regulates $F L C$ by affecting its chromatin structure [8]. VERNALIZATION INSENSITIVE 3 (VIN3), which encodes a PHD-finger protein, is necessary for epigenetic silencing of FLC [9]. Two long noncoding RNAs (IncRNAs), cold-induced long antisense RNA (COOLAIR) and cold-assisted intronic noncoding RNA (COLDAIR), are responsible for transcriptional shutdown of FLC [1011].

The effects of the autonomous, age, and gibberellin pathways are more independent of environmental stimuli. In the autonomous pathway, FLOWERING LOCUS CA (FCA), FLOWERING LOCUS D (FLD), FLOWERING LOCUS KH DOMAIN(FLK), FLOWERING LOCUS PA (FPA), FLOWERING LOCUS VE (FVE), FLOWERING LOCUS Y $(F Y)$, and $\angle U M I N I D E P E N D E N S(L D)$ participate in repressing FLC to accelerate flowering [5]. In the age pathway, miR156-targeted SQUAMOSA PROMOTER BINDING LIKE (SPL) transcription factors and miR172targeted APETALA 2 (AP2) and AP2-like genes are the two main modules [12]. In A. thaliana, DELLAs are master negative regulators of gibberellin (GA) signal transduction. Upon binding to GA, GIBBERELLIN INSENSITIVE DWARF1 (CID1) undergoes a conformational change, which creates a surface for the binding of DELLAs to form a GA-GID1-DELLA complex. DELLAs are then recruited to E3 ubiquitin ligase SCF ${ }^{\text {SLY1/GID2 }}$ for polyubiquitination, leading to the degradation of DELLAs by the 26S proteasome [13]. Furthermore, GA 20oxidases (GA20ox1-5), GA 3-oxidases (GA3ox1-3), and GA 2-oxidases (GA2ox1-5) are involved in the GA pathway [5].

The ambient temperature pathway controls flowering in response to the daily growth temperature. SHORT VEGETATIVE PHASE (SVP) plays a key role in this pathway by reducing $F T$ transcription at lower temperatures $[3,5]$.

Brassica rapa and $A$. thaliana both belong to Brassicaceae family and share a common ancestor, so they are closely related. $B$. rapa shares their ancestral polyploidization events $(\gamma, \beta$, and $\alpha)$, and experiences an additional whole genome triplication (WGT) event after divergence from $A$. thaliana [14]. Thus, the genetic pathways controlling flowering time in $B$. rapa are more complex than those in $A$. thaliana because there are multiple copies of paralogs. Two paralogs of FT (BrFT1 and BrFT2) are found in B. rapa, and a transposon insertion in BrFT2 induces late flowering [15]. Three paralogs of SOC1 (Br004928, Br000393, and Br009324) are expressed, and at least two of them have been predicted to play a role in flowering in a natural population [16]. Overexpression of BrSOC1/BrAGL20 in B. napus results in early flowering [17]. B. rapa comprises four 
FLC genes, namely, BrFLC1, BrFLC2, BrFLC3, and BrFLC5 [18]. BrFLC1, BrFLC2, and BrFLC3, syntenic orthologs of $A t F L C$, have been found to negatively regulate flowering [19-24]. A recent study has shown that $B r F L C 5$ is a weak regulator of flowering time [25]. Two FR/paralogs in B. rapa, BrFRla and BrFRIb, are activators of $B r F L C$ [20]. In vernalized $B$. rapa, DNA demethylation of two subunits of casein kinase II (CK2), BrCKA2 and $B r C K B 4$, shortens the period of circadian clock associated 1 (BrCCA1) [26]. In B. rapa, a pakchoi MADS AFFECTING FLOWERING (MAF) gene, BCMAF1, delays flowering by directly activating BCMAF2 and repressing $B C A P 3$ [27]. BCMAF2 can directly activate BCTEM1 and repress flowering [28]. Two $B$. rapa $G /$ alleles are responsible for rescuing the late-flowering phenotype of an Arabidopsis gi-201 mutant [29].

Chinese cabbage is the most leafy $B$. rapa crop in East-Asian countries, composed of a large number of tightly wrapped heading leaves. Flowering time is an important agronomic trait for Chinese cabbage, and premature bolting can severely reduce crop yield and quality. In the present study, we characterized an earlybolting Chinese cabbage mutant identified from an EMS-mutagenized population. By performing MutMap and kompetitive allele-specific polymerase chain reaction (KASP) genotyping analyses, a nonsynonymous base substitution in Brebm3 was identified to cause the mutant phenotype. The expression pattern of the causal gene Brebm3 was comprehensively analyzed by evaluating spatiotemporal expression, promoter activity, and subcellular localization. Transcriptome profiling was conducted to identify potential Brebm3regulated genes responsible for flowering time in Chinese cabbage. We expected our findings to be of great significance for further study of the molecular mechanism of bolting and flowering in Chinese cabbage.

\section{Results}

\section{Morphological characteristics and genetic analysis of the mutant ebm3}

Following EMS treatment, $528 \mathrm{M}_{0}$ lines were obtained. By continuous identification and further screening for generations, the mutant ebm3 exhibiting obvious early-bolting characteristics in spring and autumn cultivation was selected as the study material. Except for curled leaves, the mutant emb3 showed no other pleiotropic effects when compared with the wild-type line 'FT' (Fig. 1a).

Under normal cultivation conditions in autumn, the wild-type line 'FT' will not premature bolting without exposure to a prolonged cold period (vernalization); however, but the mutant emb3 exhibited obvious bolting under these conditions. To more intuitively assess the characteristics of the mutant, three indices, squaring period (SP), flowering time (FT), and days to reaching a $10 \mathrm{~cm}$-high elongated floral stalk (DE), were measured in 30 individuals and the average values are presented. SP, FD, and DE of the mutant ebm3 were 40,43 , and 46 days, respectively.

The reciprocal cross $F_{1}$ generation had the same phenotype as the wild-type line ' $F T$ ', indicating that the earlybolting phenotype of the mutant $e b m 3$ was recessive and controlled by nuclear gene. In the $F_{2}$ generation, 1,225 and 401 individuals exhibited the wild-type line ' $\mathrm{FT}$ ' and mutant ebm3 phenotype, respectively. This segregation ratio was consistent with the Mendelian ratio of 3:1 segregation $\left(\chi^{2}=0.08<\chi_{0.05}^{2}=3.84\right)$. In addition, all $518 \mathrm{BC}_{1}\left(\mathrm{~F}_{1} \times{ }^{\prime} \mathrm{FT}\right.$ ') generation individuals exhibited the phenotype of the wild-type line ' $\mathrm{FT}$ '. For 
the $\mathrm{BC}_{1}\left(\mathrm{~F}_{1} \times e b m 3\right)$ generation, 264 and 272 individuals exhibited the wild-type line ' $\mathrm{FT}$ ' and mutant ebm3 phenotype, respectively. This $1: 1$ segregation ratio was consistent with the expectations $\left(\chi^{2}=0.09<\chi^{2}{ }_{0.05}=\right.$ 3.84). These data indicated that the phenotype of the mutant $e b m 3$ was controlled by a single, recessive nuclear gene (Table 1).

Table 1

Genetic analysis of the early-bolting mutant ebm3 of Chinese cabbage

\begin{tabular}{|lcccccc|}
\hline Generation & 'FT' & ebm3 & Total & Segregation Ratio & Expected Ratio & $\chi^{2}$ \\
\hline $\mathrm{P}_{1}\left({ }^{\prime} F T^{\prime}\right)$ & 92 & 0 & 92 & & & \\
\hline $\mathrm{P}_{2}(e b m 3)$ & 0 & 81 & 81 & & & \\
$\mathrm{~F}_{1}\left(\mathrm{P}_{1} \times \mathrm{P}_{2}\right)$ & 192 & 0 & 192 & & & \\
\hline $\mathrm{F}_{1}\left(\mathrm{P}_{2} \times \mathrm{P}_{1}\right)$ & 184 & 0 & 184 & & & \\
$\mathrm{BC}_{1}\left(\mathrm{~F}_{1} \times \mathrm{FT}^{\prime}\right)$ & 518 & 0 & 518 & & $1: 1$ & 0.08 \\
\hline $\mathrm{BC}_{1}\left(\mathrm{~F}_{1} \times e b m 3\right)$ & 264 & 272 & 536 & $0.97: 1$ & $3: 1$ & 0.09 \\
\hline $\mathrm{F}_{2}$ & 1225 & 401 & 1626 & $3.05: 1$ & & \\
\hline
\end{tabular}

\section{Identification of the causal gene of the mutant ebm3}

Sequencing produced $48.75 \mathrm{~Gb}$ of raw data. After filtering, $18.98 \mathrm{~Gb}, 9.19 \mathrm{~Gb}$, and $20.55 \mathrm{~Gb}$ clean data were obtained for the ' $\mathrm{FT}$ ', ebm3, and $\mathrm{F}_{2}$ ebm3 library, respectively. Sufficient data were produced for each library, the sequencing data were of sufficient quality (Q20 $\geq 93.69 \%, Q 30 \geq 88.04 \%)$, and the GC distribution (37.55-42.77\%) was normal (Additional file 2: Table S1). The clean reads were aligned to the B. rapa reference genome (v3.0). The mapping rate was $97.95 \%, 97.37 \%$, and $97.31 \%$ for the ' $F T^{\prime}$ ', ebm3, and $F_{2}$ ebm3 library, respectively, corresponding to an average read coverage of 48.00, 22.46, and $21.17 \mathrm{X}$ (Additional file 2: Table S2). The mapped reads were normal and could be used for subsequent SNP detection. In total, 414,354 SNPs were detected in the ' $\mathrm{FT}$ ' and ebm3 library, of which 457 homozygous nonsynonymous loci were gained to calculate SNP index in $\mathrm{F}_{2-}$ ebm3 library. And then these loci that the SNP index $<0.3$ were filtered out. To evaluate the distribution of the SNP index physically mapped across the $B$. rapa chromosomes, we used an sliding window method with a 1-Mb window size and 10-kb step size in $\mathrm{F}_{2}$ ebm3 library. Here, we only showed the distribution of the SNP index in offspring pool on Chromosome A04, because it was the chromosome where the candidate loci were located (Fig. 1b). To further confirm the candidate loci, these above SNPs were screened as follows: retain loci with SNP index $=1$; filter out not-typical EMS mutant loci; retain loci large-effect. Finally, six SNPs $(3,407,432,6,258,734,13,129,878,18,591,168,21,580,928$ and $20,708,402$ ) were identified on chromosome A04, including five nonsynonymous sites in exons and one alternative splice site in an intron (Table 2). 
Table 2

List of the candidate SNPs identified by MutMap analysis

\begin{tabular}{|c|c|c|c|c|c|c|}
\hline ID & Pos & Ref & Alt & $\begin{array}{l}\text { SNP } \\
\text { index }\end{array}$ & Variant & Description \\
\hline BraA04g005220.3C & $3,407,432$ & G & $A$ & 1 & nonsynonymous & $\begin{array}{l}\text { CDT1-like protein b } \\
\text { isoform X3 }\end{array}$ \\
\hline BraA04g008870.3C & $6,258,734$ & G & $\mathrm{T}$ & 1 & nonsynonymous & $\begin{array}{l}\text { LOW QUALITY PROTEIN: } \\
\text { short-chain type } \\
\text { dehydrogenase/reductase }\end{array}$ \\
\hline BraA04g017190.3C & $13,129,878$ & C & $\mathrm{T}$ & 1 & nonsynonymous & $\begin{array}{l}\text { histone-lysine } \mathrm{N} \text { - } \\
\text { methyltransferase CLF } \\
\text { isoform X1 }\end{array}$ \\
\hline BraA04g026040.3C & $18,591,168$ & C & $\mathrm{T}$ & 1 & nonsynonymous & LEA protein group 3 \\
\hline BraA04g031990.3C & $21,580,928$ & C & $\mathrm{T}$ & 1 & nonsynonymous & $\begin{array}{l}\text { 39S ribosomal protein } \\
\text { L46, mitochondrial-like }\end{array}$ \\
\hline BraA04g030150.3C & $20,708,402$ & G & A & 1 & splicing & $\begin{array}{l}\text { signal recognition particle } \\
14 \mathrm{kDa} \text { protein-like }\end{array}$ \\
\hline
\end{tabular}

To verify the reliability of these six candidate SNPs, the sequences surrounding them were amplified from DNA from the mutant $e b m 3$ and wild-type line ' $F T$ '. Sequence alignment results showed that all SNPs were real (data not shown), and the sequencing peak of the C/T allele of SNP 13,129,878 was displayed in Fig. 1c.

We conducted genotyping analysis of $200 \mathrm{~F}_{2}$ individuals to confirm the causal SNP for the early-bolting mutant phenotype. A KASP assay showed that SNP 13,129,878 of BraA04g017190.3C co-segregated with the mutant phenotype in the $F_{2}$ individuals. All $F_{2}$ individuals exhibited a T:T genotype, whereas the wild-type line 'FT' was C:C genotype (Fig. 1d). For the other five SNPs, recombinants (C:T genotype) were detected in the $F_{2}$ individuals, indicating these SNPs did not co-segregate with the mutant phenotype (data not shown). These results confirmed that BraA04g017190.3C, harboring SNP 13,129,878, was the causal gene of the mutant ebm3. Gene annotation confirmed that BraA04g017190.3C encoded an important histone methyltransferase, CLF. Loss-of-function of $A$. thaliana homologous $C L F(A t 2 g 23380)$ causes an early flowering phenotype and upwardly curled leaves [30]. In this study, the causal gene of the mutant ebm3 is referred to as Bremb3.

The full-length gene sequence of Bremb3 was found to be 4,406 bp, and Bremb3 consists of 17 exons and 16 introns (Fig. 2a). Sequence alignment of the mutant ebm3 and wild-type line 'FT' showed that besides SNP $13,129,878$ in the 14th exon, there was no variation. The coding sequence of Bremb3, 2,715 bp in length, encodes a protein of 904 amino acids with a molecular weight of $1000 \mathrm{kDa}$ and a theoretical pl of 90.5 . The SNP 13,129,878 $(\mathrm{C} \rightarrow \mathrm{T})$ of Brebm3 causes an amino acid substitution from serine $(\mathrm{S})$ to phenylalanine $(\mathrm{F})$ at residue 766 (Fig. 2b). The amino acid substitution is localized in a typical SET domain that is highly conserved among diverse species (Fig. 2c; The original figure refers to Additional file 1: Figure S1). 
To study the relative expression levels of Brebm3 in different tissues, RNA from root, stem, leaf, bud, flower, and pod of the wild-type line 'FT' was used as a template for qRT-PCR. The data showed that Brebm3 expression was the highest in the flower, followed by the bud, leaf, and pod, with extremely low expression in the stem (Fig. 3a).

\section{Brebm3 promoter activity}

We analyzed Brebm3 promoter activity in A. thaliana tissues by using the fusion vector Brebm3 pro:GUS. Following screening based on hygromycin resistance and the GUS reporter gene, 32 transgenic plants were obtained (Fig. 3b, c; The original figure of Fig. 3c refers to Additional file 1: Figure S2). Tissues (root, stem, leaf, inflorescence, and pod) of homozygous $T_{2}$ generation transgenic plants were stained in a GUS histochemical assay. Analysis of the transformed plants showed that Brebm3 transcriptional activity was the highest in the inflorescence, followed by leaf and pod (Fig. 3d). These results were in line with those of spatiotemporal expression analysis, indicating that ebm3 expression shows a tissue-specific pattern.

\section{Brem3 is located to the nucleus}

To detect the subcellular localization of Brebm3, we constructed recombinant 35S:GFP-Brebm3 plasmid for transiently expression. Co-localization analysis of GFP and mKate fluorescent signals in the transformed Arabidopsis mesophyll cell protoplasts indicated that 35S:GFP-Brebm3 vector was exclusively located in the nucleus, suggesting that Brem3 is a nucleoprotein. Whereas the $35 \mathrm{~S}$ :GFP control vector was detected within both the nucleus and cytoplasm (Fig. 4).

\section{Transcriptome profiling of the mutant ebm3}

We further conducted RNA-Seq to analyze the molecular mechanism of Brebm3 in regulating early bolting in Chinese cabbage. After filtering and quality control, $22.32 \mathrm{~Gb}$ and $20.94 \mathrm{~Gb}$ of clean reads were obtained for the ' $\mathrm{FT}$ ' and ebm3 library, respectively. Sufficient data were produced for each library, the sequencing quality (Q20 $\geq 99.91 \%$, Q30 $\geq 98.41 \%$ ) was sufficient, and the GC distribution (46.50-47\%) was normal (Additional file 2: Table S3). On average, $69.01 \%$ and $68.93 \%$ of clean reads from 'FT' and ebm3 libraries, respectively, were uniquely mapped to the $B$. rapa reference genome (v3.0) (Additional file 2: Table S4). In total, 1,906 DEGs, including 1,079 up- and 827 downregulated genes, were identified in the mutant ebm3. To determine their biological functions, we used GO term and KEGG pathway enrichment analysis. 1,612 DEGs were mapped to 272 significantly enriched GO terms ( $p$ vaule $\leq 0.03$ ) (Additional file 1: Figure S3). The most significantly enriched GO terms were "transcription, DNA-templated" in biological process, "plasma membrane" in cellular component, and "transcription factor activity, sequence-specific DNA binding" in molecular function. 944 DEGs were assigned to 19 significantly enriched KEGG pathways ( $p$ vaule $\leq 0.03$ ), including starch and sucrose metabolism, phenylalanine metabolism, and circadian rhythm-plant (Additional file 1: Figure S4). 
Flowering is an essential stage in the life cycle of higher plants and is tightly controlled by complex molecular pathways. To further explore the molecular mechanism underlying the early-bolting phenotype of the mutant $e b m 3$, we conducted an in-depth analysis of the transcriptome data. The causal gene Brebm3

(BraA04g017190.3C) was not significantly differentially expressed between the mutant ebm3 and wild-type line'FT' (Additional file 2: Table S5; Fig. 5a). The floral integrator genes FT, TSF, TFL 1, and SOC1, the vernalization pathway-related genes $F L C$ and $F R I$, the ambient temperature-related gene SVP, the photoperiod pathway-related gene $G l$, age pathway-involved genes $S P L 3, S P L 9$ and $S P L 15$, gibberellin pathway-involved genes GA200X1-4, floral homeotic genes AG, AGL19, SEP1/AGL2, SEP2/AGL4 and FUL/AGL8 were detected in our data. The SOC1 genes (BraA04g031640.3C, BraA05g005370.3C, and BraA03g023790.3C), two AG genes (BraA03g048590.3C and BraA01g010430.3C), AGL19 (BraA01g013570.3C), SEP1/AGL2 (BraA10g023780.3C), SEP2/AGL4 (BraA01g044460.3C) were significantly upregulated in the mutant ebm3 as compared to wild-type line 'FT' (Additional file 2: Table S5). We assessed Brebm3, SOC1, and FLC gene expression by RT-qPCR to verify the reliability of the RNA-seq data. As shown in Fig. 5, the expression patterns of the eight genes were generally consistent with the transcriptome profile.

\section{Discussion}

Chinese cabbage is generally grown in the autumn and spring seasons. The harvest period of spring varieties coincides with the off-season supply, accommodating for the annual demand. Unlike autumn varieties, the seedlings of spring varieties require exposure to a prolonged cold period. Premature bolting, which mostly occurs in spring varieties and is caused by low-temperature and long-day conditions, severely reduces crop yield and quality. To overcome restrictions related to planting season and geographic distribution, diverse spring varieties with high bolting resistance have been selected through the incorporation of genetic resources in the past few years [31].

A good understanding of the molecular mechanism of flowering time can accelerate the breeding of boltingresistant varieties [20]. To adapt to the diverse agro-environments, vegetable crops have employed a complex and elaborate network that tightly controls flowering time. Mutants are important materials for plant functional genomics studies. The genetic basis of natural variation in flowering time has been extensively evaluated in quantitative trait loci (QTL) studies [32-35]. However, there is insufficient natural variation for effective research due to the low probability. Here, we characterized an EMS-induced early-bolting mutant, ebm3, with curled leaves, which was derived from a Chinese cabbage DH line 'FT' (Fig. 1a). The genetic background of the mutant $e b m 3$ was relatively homozygous, and highly consistent with that of the wild-type line 'FT', which was conducive to highlight the bolting phenotype caused by the causal gene. Genetic analysis showed that the mutant trait was quality character, controlled by a single recessive nuclear gene (Table 1 ). Multi-season planting indicated that the early-bolting trait was genetically stable and not affected by external factors. Therefore, the mutant $e b m 3$ is an ideal material to study important node genes in the flowering regulatory pathways in Chinese cabbage.

EMS mutagenesis has multiple advantages, such as high mutation frequency, easy screening, and stable inheritance, which is why EMS is the most widely used chemical mutagen in plants [36]. The combination of 
high-throughput sequencing with bulk segregant analysis (BSA) has laid the foundation for rapid mining of new genes using mutants, which has greatly facilitated functional genome studies. In our study, we used a modified MutMap method and KASP genotyping to map the causal gene. Brebm3 (BraA04g017190.3C), encoding histone methyltransferases CLF, was found to be responsible for the early-bolting trait (Fig. $1 \mathrm{~b}$-d). A nonsynonymous SNP in the 14th exon of Brebm3 caused an amino acid substitution from S to F (Fig. 2a). Unlike loss-of-function of Arabidopsis CLF, a single amino acid change of in the Enhancer of zeste $(\mathrm{E}(\mathrm{z}))$ ortholog $C L F$, clf-59 retained $F L C$ repression by promoting histone $\mathrm{H} 3$ lysine 27 trimethylation (H3K27me3) deposition in FLC chromatin, causing early flowering [37]. Sequence comparison of CLF of various species revealed that the protein has a highly conserved SET domain, and the nonsynonymous SNP was located in this domain (Fig. 2b, c). The SET domain is a 130-140-amino acid evolutionarily conserved sequence motif [38]. SET domain proteins have been characterized in diverse plant species, including Arabidopsis, rice, maize, barley, grapevine, and poplar [39-44]. Most histone lysine methyltransferases (HKMTases) have a conserved SET domain, and the HKMTases with SET domain are named SET DOMAIN GROUP (SDG) proteins. Plant SDG proteins are generally divided into four classes: suppressor of protein-effect variegation 3-9 (SU(VAR)3-9); E(z); trithorax (TRX); and absent, small or homeotic disks 1 (ASH1). Detrimental effects of mutations in $\mathrm{E}(\mathrm{z}), \mathrm{TRX}$, and $\mathrm{ASH} 1$ mark the importance of the SET domain in plant growth and development [45]. Moreover, SDG proteins have been suggested to affect flowering time. Mutations in five Arabidopsis SDG genes, including ASHR3/SDG2 [46], ASHH2/SDG8/EFS[47], ATX1/SDG27 [48], ATXR7/SDG25 [49], and CLF/SDG1 [30], cause an early-flowering phenotype, and mutations in Arabidopsis $A S H H 1 / S D G 26$ [50], and three rice genes, including SDG708 [51], SDG724 [52] and SDG725 [53], confer a lateflowering phenotype. The present and previous studies indicate that an amino acid substitution in the SET domain of Brebm3 is expected to cause the early-bolting phenotype in Chinese cabbage.

Epigenetic factors play crucial roles in flowering regulation by activating or repressing the transcription of flowering genes. Two functionally distinct multiprotein complexes of the Polycomb Group (PcG), PcG Repressive Complex 1 (PRC1) and PRC2, are the core epigenetic factors in eukaryotes [54]. PRC2 is a key repressive epigenetic mark, which maintains the repressed state of a target gene by catalyzing H3K27me3 [55]. In A. thaliana, PRC2 acts on various growth and developmental processes, including leaf morphology, floral organogenesis, cell pluripotency, vegetative-to-reproductive phase transition, and embryonic development [58-61]. In A. thaliana, CLF is the main component of the E(z) subunit of PRC2 [62]. Extensive evidence supports that CLF maintains suppressed expression of $F L C$ and $F T$, as well as that of several floral homeotic genes, including $A G, A G L 19$, and $S E P 3$ [30,60,63-67]. As a typical example of reprogramming of epigenetic states in plants, $\mathrm{H} 3 \mathrm{~K} 27 \mathrm{me} 3$ repressive marks on $F L C$ can be erased by ELF6 histone demethylases during seed development [68]. A noncoding RNA transcribed from the second intron of $A G$ associated with CLF can silence $A G$ expression by mediating H3K27m3 deposition to form repressive chromatin [69]. The temporal-specific interaction of NF-YC and CLF mediates epigenetic regulation by derepressing $F T$ expression in photoperiod-induced flowering [4]. Loss-of-function of ASHH1/SDG26 retains SOC1/AGL20 repression by reducing $\mathrm{H} 3 \mathrm{~K} 4 \mathrm{me} 3$ and $\mathrm{H} 3 \mathrm{~K} 36 \mathrm{me} 3$ deposition in SOC1/AGL2O chromatin, resulting in the late-flowering phenotype [50]. A tilling mutant of $B$. rapa, braA.clf-1 (GIn615Stop), displayed small plant size, altered floral development, and curled leaves due to reduced H3K27me3 and high expression levels of floral homeotic genes such as $A G$ and $A G L$ loci [70]. In the present study, transcriptome profiling revealed that $A G$ and $A G L$ loci, e.g., SOC1/AGL20, AGL19, SEP1/AGL2, SEP2/AGL4, were significantly upregulated in the mutant ebm3 
(Additional file 2: Table S5). Therefore, it is reasonable to speculate that mutation in Brebm3 mediates reduced $\mathrm{H} 2 \mathrm{~K} 27 \mathrm{me} 3$ deposition and high expression of the $A G$ and $A G L$ loci in Chinese cabbage.

\section{Conclusions}

The transition to flowering is an essential developmental stage in the plant life cycle. Plants need to flowering in the most favorable conditions to ensure maximal reproductive success. Timely flowering is conducive to crop production, harvesting, and marketing. In this study, based on MutMap and KASP genotyping analyses, Brebm3, encoding the histone methyltransferase CLF, was determined to control the early-bolting trait in Chinese cabbage. Brebm3 was highly expressed in the floral organs, and the translation product localized in the nucleus. Transcriptome profiling was conducted to identify potential CLF-repressed genes in mutant ebm3. Collectively, our findings will be invaluable for understanding the molecular mechanism of flowering time in Chinese cabbage.

\section{Methods}

\section{Plant materials and genetic analysis}

The Chinese cabbage DH line ' $\mathrm{FT}$ ' was used as a wild-type line in this study propagated from Chinese cabbage variety 'Fukuda 50', which was screened by Shenyang greenstar Chinese cabbage research institute (Shenyang, China) [71]. An early-bolting mutant with stable inheritance was obtained from 'FT' by multigenerational screening after EMS mutagenesis, and was designated ebm3. The mutant generation method has been described in detail in Fu et al. [72]. To study the inheritance characteristics, the mutant ebm3 and wild-type line ' $F T^{\prime}$ ' were used as parents. An $\mathrm{F}_{1}$ generation obtained by a reciprocal cross was selfcrossed to obtain an $F_{2}$ segregating generation. The $F_{1}$ generation was backcrossed with both parents to obtain a $\mathrm{BC}_{1}$ population. The segregation ratios of the $\mathrm{F}_{2}$ and $\mathrm{BC}_{1}$ populations were analyzed using the chisquare test. The $\mathrm{F}_{2}$ population was also used for mutant gene identification and genotyping. Individual plants were grown in a greenhouse at Shenyang Agricultural University.

A. thaliana ecotype Columbia-0 (Col-0) was obtained from the Arabidopsis Biological Resource Center (ABRC; http://abrc.osu.edu) and preserved by the Liaoning Key Laboratory of Genetics and Breeding for Cruciferous Vegetable Crops at Shenyang Agricultural University. All Arabidopsis plants were grown in a growth chamber at Shenyang Agricultural University. Culture conditions were as described by Wang et al. [73].

\section{Evaluation of bolting characteristics}

Three bolting characteristics were measured, i.e., SP, DE, and FT, as previously reported by Yu et al. [74]. Thirty mutant ebm3 plants (10 individuals per replication, with three replications each) were selected for a survey of bolting characteristics in comparison with wild-type line ' $\mathrm{FT}$ ' under natural conditions in the autumn of 2017.

\section{Candidate SNP identification by the MutMap method}


A modified MutMap method was used to identify the candidate gene for the mutant ebm3 [75]. DNA was extracted from $15 \mathrm{~F}_{2}$ individuals with the early-bolting phenotype and the parental lines using a DNAsecure Plant Kit (Tiangen Biotech Co., Ltd., Beijing, China) according to the manufacturer's instructions. Equal amounts of each DNA from the $15 \mathrm{~F}_{2}$ individuals were mixed to construct an offspring pool. Sequencing libraries of the mutant ebm3 (ebm3), wild-type line ' $\mathrm{FT}$ ' ('FT'), and offspring pool ( $\mathrm{F}_{2}$-ebm3) were generated using a TruSeq Nano DNA HT Sample preparation Kit (Illumina, San Diego, CA, USA). The libraries were

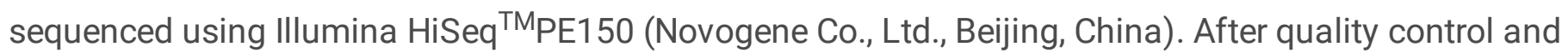
filtration, the clean reads of each sample were aligned to the $B$. rapa reference genome (http://brassicadb.org/brad/, v3.0) using Burrows-Wheeler Alignment tool (BWA) [76]. Alignment files were converted to BAM files using the SAMtools software [77]. SNP calling was performed using GATK [78] and annotated using ANNOVAR [79]. The screened SNPs between the M and W library were used to calculate the SNP index in offspring-pool library. The sliding window method was used to determine the SNP index of the whole genome in offspring pool library.

\section{SNP genotyping by KASP}

To verify the real existence of the candidate SNP, a sequence surrounding the locus was amplified using DNA from the mutant ebm3 and wild-type line 'FT' and the primer pair 5'-ATACTTTGCTTTGGTTGACTCTAC-3' and 5'-TCGTGTTTACTTACACTGTTCTGT-3'. Purified PCR product was ligated into the PMD 18-T Vector (Takara Biotech Co., Ltd., Dalian, China), and transformed into TOP10 competent cells (ComWin Biotech Co., Ltd., Beijing, China). The recombinant plasmid was sequenced by Sanger sequencing (Genewiz Inc., Tianjin, China). Sequence alignment was performed using the SeqMan software.

The candidate SNP was confirmed using a KASP assay to detect whether the locus co-segregated with the mutant phenotype. For KASP genotyping, DNA from $200 \mathrm{~F}_{2}$ individuals with the early-bolting phenotype was used. Two allele-specific primers carrying the fluorescence probes FAM and HEX and the candidate SNP at the 3' end (Primer_AlleleFAM: AGgTTTTACTTGgAATATCTGATGTATC; Primer_AlleleHEX:

CAGGTTTTACTTGGAATATCTGATGTATT), and a common genome-specific primer (Primer_Common: GTTACGCATCTACTATACCTTTAGGAAAG), were designed following standard KASP guidelines of the laboratory of the Government Chemist (LGC http://www.lgcgenomics.com/). The primer mixture was prepared as recommended by LGC Genomics. PCR mixture preparation and cycling were conducted as described by Xi et al. (2018). Fluorescence data were read using a 7900HT Fast Real-Time PCR System (Applied Biosystems, Foster City, CA , USA).

\section{Quantitative reverse transcription-PCR (qRT-PCR)}

Total RNA of each sample was extracted using TRIzol Reagent (Invitrogen, Carlsbad, CA, USA). First-strand cDNA was synthesized using FastKing gDNA Dispelling RT SuperMix (Tiangen Biotech Co., Ltd., Beijing, China). The reaction system was performed with UltraSYBR Mixture (ComWin Biotech Co., Ltd., Beijing, China). PCR amplification was run in a QuantStudio ${ }^{\mathrm{TM}} 6$ Flex Real-Time PCR System (Applied Biosystems, Carlsbad, CA, USA). The Actin gene was selected as an internal control. Relative gene expression data were 
calculated by the $2^{-\triangle \Delta \mathrm{Ct}}$ method [80]. The data were analyzed using the QuantStudio ${ }^{\mathrm{TM}} 6$ Flex Manager software. Three technical and biological replications were included for each sample. The qRT-PCR primer pairs were listed in Additional file 2: Table S6.

\section{Promoter activity assay}

The promoter sequence (2,000 bp upstream of the initiation codon) of Brebm3 was amplified from DNA of the wild-type line ' $\mathrm{FT}$ ', using the primer pair 5'-ccgggatccTCTAGAgcgaagccaagtagtaagcact-3' and 5'gcaggtcgacTCTAGAtgtcgaggagccagatcgga- $3^{\prime}$ (uppercase letters indicate an $X$ bal site). The amplification product was digested with $X b a l$ and ligated into the pC1301 lgT vector containing fused GUS reporter gene. The recombinant plasmid was introduced into Agrobacterium tumefaciens strain GV3103. A. tumefaciensmediated transformation was used to transfer the Brebm3 pro:GUS vector into $A$. thaliana Col-0 by the floral dip method. Transgenic plants were screened on $0.5 \times$ Murashige and Skoog (MS) medium containing 0.25 $\mathrm{mg} \mathrm{L}^{-1}$ hygromycin. The GUS reporter gene was amplified from DNA of all hygromycin-resistant plants, using the primer pair 5'- AACCACAAACCGTTCTACTTTACTG-3' and 5'-TACATTACAAGACGCTGCGAGT-3'. A GUS histochemical assay was performed on various tissues (root, stem, leaf, inflorescence and pod) of the transgenic plants [81].

\section{Subcellular localization}

The full-length Brebm 3 coding sequence without the stop codon was amplified from cDNA of the wild-type line ' $\mathrm{FT}$ ', using the primer pair 5'- cgatCACCTGCaaaacaacatggcgtcgggagcttcgcc-3' and 5'cagtCACCTGCaaaatacaagcaaccttcttgggtctac-3' (uppercase letters indicate an Aarl site). The amplification product was digested with Aatl and inserted into the pBWA(V)HS-ccdb-GLosgfp vector, resulting in an Nterminal fusion vector with GFP under the control of the CaMV35S promoter (35S:GFP-Brebm3). The 35S:GFP vector was used as a control. The constructs were respectively transiently transformed into $A$. thaliana mesophyll cell protoplasts, as described by Wang et al. [70]. The pBWA(V)HS-NLS-mKATE vector was served as a nucleus marker. Fluorescence data were obtained by confocal laser-scanning microscope (Leica TCS SP8, Wetzlar, Germany).Excitation wavelengths used were $488 \mathrm{~nm}$ for GFP and $561 \mathrm{~nm}$ for mKate. Emission wavelengths were $507 \mathrm{~nm}$ for GFP and $580 \mathrm{~nm}$ for mKate.

\section{Transcriptome profiling}

When the mutant ebm3 reached the critical point of bolting, total RNA was extracted from the SAM of mutant and wild-type line ' $F T^{\prime}$, with three biological replications (designated emb3-1, emb3-2, emb3-3, 'FT'-1, 'FT'-2, and 'FT'-3). RNA quantity and purity was analyzed using a Bioanalyzer 2100 and RNA 6000 Nano LabChip Kit (Agilent Technologies, SantaAdditional file 2: Clara, CA, USA). Following purification and fragmentation, the cleaved RNA fragments were reverse-transcribed to create CDNA libraries using a mRNASeqsample preparation kit (Illumina, San Diego, CA, USA). The libraries were paired-end sequenced using an Illumina HiSeq 4000 platform (LC-Bio Technology Co., Ltd., Hangzhou, China). Following quality control and filtration, 
the clean reads were aligned to the $B$. rapa reference genome (v3.0) using HISAT. StringTie was used to assemble the alignments into transcripts and to compute transcript abundance by calculating Fragments Per Kilobase of transcript per Million mapped reads (FPKM). Differentially expressed genes (DEGs) were defined based on $\mid \log _{2}$ (fold change) $\mid \geq 1$ and $p<0.05$, using the R package Ballgown [82]. Functional analysis of the DEGs included Gene Ontology (GO) and Kyoto Encyclopedia of Genes and Genomes (KEGG) pathway analyses [83-84].

\section{Sequence characteristic analyses}

The gene structure was displayed using the Gene Structure Display Server (http://gsds.cbi.pku.edu.cn/). Physical and chemical characteristics were predicted using Protparam (http://web.expasy.org/protparam). Domains were identified and annotated using Simple Modular Architecture Research Tool (http://smart.emblheidelberg.de/).

\section{Declarations}

\section{Ethics approval and consent to participate}

Not applicable

\section{Consent to publish}

Not applicable

\section{Availability of data and material}

The datasets supporting the conclusions of this article are included within the article and its additional files. Any other datasets used and/or analyzed during the current study are available from the corresponding author on reasonable request.

\section{Competing interests}

All the authors declare that they have no competing interests.

\section{Funding}

This work was supported by grants from the National Natural Science Foundation of China (No.31772298). The funding played roles in the design of the study and collection, analysis, and interpretation of data.

\section{Authors' contributions}


CT and JR analyzed the data and drafted the manuscript. LW, WF, JZ, and MQ participated in the creation of materials and performed the experiments. $\mathrm{XY}, \mathrm{HF}$ and $\mathrm{ZL}$ directed the whole study including designing experiments and revising the manuscript. All authors have read and approved the final manuscript.

\section{Acknowledgements}

We thank Editage (www.editage.cn) for English language editing.

\section{Authors details}

Liaoning Key Laboratory of Genetics and Breeding for Cruciferous Vegetable Crops, Department of Horticulture, Shenyang Agricultural University, Shenyang 110866, People's Republic of China

\section{References}

1. Bloomer RH, Dean C. Fine-tuning timing: natural variation informs the mechanistic basis of the switch to flowering in Arabidopsis thaliana. J Exp Bot. 2000;68(20):5439-5452.

2. Shea DJ, Itanashi E, Takada S, Fukai E, Kakizaki T, Fujimoto R, Okazaki K. The role of FLOWERING LOCUS $C$ in vernalization of Brassica: the importance of vernalization research in the face of climate change. Crop Pasture Sci. 2018;69(1):30-39.

3. Fornara F, de Montaigu A, Coupland G. SnapShot: Control of flowering in Arabidopsis. Cell. 2010;141(3):550,550.e1-2.

4. Liu X, Yang YH, Hu YL, Zhou LM, Li YG, Hou XL. Temporal-Specific interaction of NF-YC and CURLF LEAF during the floral Transition regulation flowering. Plant Physiol. 2018;177(1):105-114.

5. Leijten W, Koes R, Roobeek I, Frugis G. Translating flowering time from Arabidopsis thaliana to Brassicaceae and Asteraceae crop species. Plants (Basel) 2018;7(4):111.

6. Srikanth A, Schmid M. Regulation of flowering time: all roads lead to Rome. Cell Mol Life Sci. 2011;68(12):2013-2037.

7. Searle I, He YH, Turck F, Vincent C, Fornara F, Kröber S, Amasino RA, Coupland G. The transcription factor FLC confers a flowering response to vernalization by repressing meristem competence and systemic signaling in Arabidposis. Genes Dev. 2006;20(7):898-912.

8. Johanson U, Weat J, Lister S, Michaels S, Amasino R, Dean C. Molecular analysis of FRIGIDA, a major determinant of natural variation in Arabidopsis flowering time. Science. 2000;290(5490):344-347.

9. Kim DH, Sung S. Accelerated vernalization response by an altered PHD-finger protein in Arabidopsis. Plant Signal Behav. 2017;12(5):e1308619.

10. Csorba T, Questa JI, Sun, QW, Dean C. Antisense COOLAIR mediates the coordinated switching of chromatin states at FLC during vernalization. Proc Natl Acad Sci U S A. 2014;111(45):16160-16165.

11. Kim DH, Xi YP, Sung S. Modular function of long noncoding RNA, COLDAIR, in the vernalization response. PLoS Genet. 2017;13(7):e1006939. 
12. Wu G, Park MY, Conway SR, Wang JW, Weigel D, Poethig RS. The sequential action of miR156 and miR172 regulates developmental timing in Arabidopsis. Cell. 2009;138(4):750-759.

13. Ito T, Okada K, Fukazawa J, Takahashi Y. DELLA-dependent and -independent gibberellin signaling. Plant Signal Behav. 2018,13(3):e1445933.

14. Wang XW, Wang HZ, Wang J, Sun RF, Wu J, Liu S.Y, Bai Y.Q, Mun JH, Bancroft I, Cheng F, Huang S, Li X, Hua W, Wang J, Wang X, Freeling M, Pires JC, Paterson AH, Chalhoub B, Wang B, Hayward A, Sharpe AG, Park BS, Weisshaar B, Liu B, Li B, Liu B, Tong C, Song C, Duran C, Peng C, Geng C, Koh C, Lin C, Edwards D, Mu D, Shen D, Soumpourou E, Li F, Fraser F, Conant G, Lassalle G, King GJ, Bonnema G, Tang H, Wang H, Belcram H, Zhou H, Hirakawa H, Abe H, Guo H, Wang H, Jin H, Parkin IA, Batley J, Kim JS, Just J, Li J, Xu J, Deng J, Kim JA, Li J, Yu J, Meng J, Wang J, Min J, Poulain J, Wang J, Hatakeyama K, Wu K, Wang L, Fang L, Trick M, Links MG, Zhao M, Jin M, Ramchiary N, Drou N, Berkman PJ, Cai Q, Huang Q, Li R, Tabata S, Cheng S, Zhang S, Zhang S, Huang S, Sato S, Sun S, Kwon SJ, Choi SR, Lee TH, Fan W, Zhao X, Tan X, Xu X, Wang Y, Qiu Y, Yin Y, Li Y, Du Y, Liao Y, Lim Y, Narusaka Y, Wang Y, Wang Z, Li Z, Wang Z, Xiong Z, Zhang Z; Brassica rapa Genome Sequencing Project Consortium. The genome of the mesopolyploid crop species Brassica rapa. Nat Genet. 2011;43(10):1035-1039.

15. Zhang XM, Meng L, Liu B, Hu YY, Cheng F, Liang JL, Aarts MGM, Wang XW, Wu J. A transposon insertion in FLOWERING LOCUS T is associated with delayed flowering in Brassica rapa. Plant Sci. 2015;241:211220.

16. Franks SJ, Perez-Sweenry B, Strahl M, Nowogrodzki A, Weber JJ, Lalchan R, Jordan KP, Litt A. Variation in the flowering time orthologs BrFLC and BrSOC1 in a natural population of Brassica rapa. PeerJ. 2015;3:e1339.

17. Hong JK, Kim SY, Kim KS, Kwon SJ, Kim JS, Kim JA, Lee SI, Lee YH. Overexpression of a Brassica rapa MADS-box gene, BrAGL20, induces early flowering time phenotypes in Brassica napus. Plant Biotechnol Rep. 2013;7(3):231-237.

18. Schranz ME, Quijada P, Sung SB, Lukens L, Amasino R, Osborn TC. Characterization and effects of the replicated flowering time gene FLC in Brassica rapa. Genetics. 2002;162(3):1457-1468.

19. Kim JS, Chung TY, King GJ, Jin M, Yang TJ, Jin YM, Kim HL, Park BS. A sequence-tagged linkage map of Brassica rapa. Genetics. 2006;174(1):29-39.

20. Takada S, Akter A, Itabashi E, Nishida N, Shea DJ, Miyaji N, Mehraj H, Osabe K, Shimizu M, TakasakiYasuda T, Kakizaki T, Okazaki K, Dennis ES, Fujimoto R. The role of FRIGIDA and FLOWERING LOCUS C genes in flowering time of Brassica rapa leafy vegetables. Sci Rep. 2019;9(1):13843.

21. Wu J, Wei KY, Cheng F, Li SK, Wang Q, Zhao JJ, Bonnema G, Wang XW. A naturally occurring InDel variation in BraA.FLC.b (BrFLC2) associated with flowering time variation in Brassica rapa. BMC Plant Biol. 2012;12:151.

22. Xiao D, Zhao JJ, Hou XL, Basnet RK, Carpio DPD, Zhang NW, Bucher J, Lin K, Cheng F, Wang XW, Bonnema G. The Brassica rapa FLC homologue FLC2 is a key regulator of flowering time, identified through transcriptional co-expression networks. J Exp Bot. 2013;64(14):4503-4516.

23. Yuan YX, Wu J, Sun RF, Zhang XW, Xu DH, Bonnema G, Wang XW. A naturally occurring splicing site mutation in the Brassica rapa FLC1 gene is associated with variation in flowering time. $J$ Exp Bot. 2009;60(4):1299-1308. 
24. Zhao JJ, Kulkarni V, Liu NN, Carpio DPD, Bucher J, Bonnema G. BrFLC2 (FLOWERING LOCUS C) as a candidate gene for a vernalization response QTL in Brassica rapa. J Exp Bot. 2010;61(6):1817-1825.

25. Xi X, Wei KY, Gao BZ, Liu JH, Liang JL, Cheng F, Wang XW, Wu J. BrFLC5: a weak regulator of flowering time in Brassica rapa. Theor App/ Genet. 2018;131(10):2107-2116.

26. Duan WK, Zhang HJ, Zhang B, Wu XT, Shao SX, Li Y, Hou XL, Liu TK. Role of vernalization-mediated demethylation in the floral transition of Brassica rapa. Planta. 2017;245(1):227-233.

27. Huang FY, Liu TK, Hou, XL. Isolation and functional characterization of a floral repressor, BcMAF1, from Pak-choi (Brassica rapa ssp. Chinensis). Front Plant Sci. 2018;9:290.

28. Huang FY, Liu TK, Tang J, Duan WK, Hou XL. BcMAF2 activates BcTEM1 and represses flowering in Pakchoi (Brassica rapa ssp. chinensis). Plant Mol Biol. 2019;100(1-2): 19-32.

29. Xie QG, Lou P, Hermand V, Aman R, Park HJ, Yun, DJ, Kim WY, Salmela MJ, Ewers BE, Weinig C, Khan SL, Schaible DLP, McClung CR. Allelic polymorphism of GIGANTEA is responsible for naturally occurring variation in circadian period in Brassica rapa. Proc Natl Acad Sci U S A. 2015;112(12):3829-3834.

30. Goodrich J, Puangsomlee P, Martin M, Long D, Meyerowitz EM, Coupland G. A Polycomb-group gene regulates homeotic gene expression in Arabidopsis. Nature 1997;386(6620):44-51.

31. Su TB, Wang WH, Li PR, Zhang B, Li P, Xin XY, Sun HH, Yu YJ, Zhang, DS, Zhao XY, Wen CL, Zhou G, Wang YT, Zheng HK, Yu SC, Zhang FL. A genomic variation map provides insights into the genetic basis of spring Chinese cabbage (Brassica rapa ssp. pekinensis) selection. Mol Plant. 2018;11(11):13601376.

32. Brachi B, Faure N, Horton M, Flahauw E, Vazquez A, Nordborg M, Bergelson J, Cuguen J, Roux F. Linkage and association mapping of Arabidopsis thaliana flowering time in nature. PLoS Genet. 2010;6(5):e1000940.

33. Long Y, Shi J, Qiu D, Li R, Zhang C, Wang J, Hou J, Zhao J, Shi L, Park Beon-Seok, Choi SR, Lim YP, Meng $\mathrm{J}$. Flowering time quantitative trait loci analysis of oilseed Brassica in multiple environments and genomewide alignment with Arabidopsis. Genetics. 2007;177(4):2433-2444.

34. Luo ZL, Wang M, Long Y, Huang YJ, Shi L, Zhang CY, LiuY, Fitt BDL, Xiang JX, Mason AS, Snowdon RJ, Liu PF, Meng JL, Zou J. Incorporating pleiotropic quantitative trait loci in dissection of c8omplex traits: Seed yield in rapeseed as an example. Theor App/ Genet. 2017;130(8):1569-1585.

35. Wang YG, Wang XS, Wang X, Zhao QN, Lv XX, Feng H. Construction of chromosome segment substitution lines of Chinese cabbage (Brassica rapa L. ssp. pekinensis) in the background of $\mathrm{RcBr}$ ( $B$. rapa L. ssp. dichotoma) and characterization of segments representing the bolting trait. Mol Breeding. 2018;38(4):35.

36. Brockman HE. de Serres FJ, Ong TM, DeMarini DM, Katz AJ, Griffiths AJ, Stafford RS. Mutation tests in Neurospora crassa. A report of the U.S. environmental protection agency gene-Tox program. Mutat Res. 1984;133(2):87-134.

37. Doyle MR, Amasino RM. A single amino acid change in the Enhancer of Zeste ortholog CURLF LEAF results in vernalization-independent, rapid flowering in Arabidopsis. Plant Physiol. 2009;151(3):16881697. 
38. Jenuwein T, Laible G, Dorn R, Reuter G. SET domain proteins modulate chromatin domains in Eu- and heterochromatin. Cell Mol Life Sci. 1998;54(1):80-93.

39. Aquea F, Vega A, Timmermann T, Poupin MJ, Arce-Johnson P. Genome-wide analysis of the SET DOMAIN GROUP family in Grapevine. Plant Cell Rep. 2011;30(6):1087-1097.

40. Kapazoglou A, Tondelli A, Papaefthimiou D, Ampatzidou H, Francia E, Stanca MA, Bladenopoulos K, Tsaftaris AS. Epigenetic chromatin modifiers in barley: IV. The study of barley polycomb group (PcG) genes during seed development and in response to external ABA. BMC Plant Biol. 2010;10:73.

41. Lei L, Zhou SL, Ma H, Zhang LS. Expansion and diversification of the SET domain gene family following whole-genome duplicationa in Populus trichocarpa. BMC Evol Biol. 2012;12:51.

42. Ng DWK, Wang T, Chandrasekharan MB, Aramayo R, Kertbundit S, Hall TC. Plant SET domain-containing proteins: structure, function and regulation. Biochim Biphys Acta. 2007;1769(5-6):316-29.

43. Springer NM, Napoli CA, Selinger DA, Pandey R, Cone KC, Chandler VL, Kaeppler HF, Kaeppler SM. Comparative analysis of SET domain proteins in maize and Arabidopsis reveals multiple duplications preceding the divergence of monocots and dicots. Plant Physiol. 2003;132(2):907-925.

44. Zhang LS, Ma H. Complex evolutionary history and diverse domain organization of SET proteins suggest divergent regulatory interactions. New Phytol. 2012;195(1):248-263.

45. Thorstensen T, Grini PE, Aalen PB. SET domain proteins in plant development. Biochim Biophys Acta. 2017;1809(8):407-420.

46. Yun JY, Tamada Y, Kang YE, Amasino RM. ARABIDOPSIS TRITHORAX-RELATED3/SET DOMAIN GROUP2 is required for the winter-annual habit of Arabidopsis thaliana. Plant Cell Physiol. 2012;53(5):834-846.

47. Xu L, Zhao Z, Dong A, Soubigous-Taconnat L, Renou JP, Steinmetz A, Shen WH. Di- and tri- but not monomethylation on histone H3 lysine 36 marks active transcription of genes involved in flowering time regulation and other processes in Arabidopsis thaliana. Mol Cell Biol. 2008;28(4): 1348-1360.

48. Pien S, Fleury D, Mylne JS, Crevillen P, Inzé D, Avramova Z, Dean C, Grossniklaus U. ARABIDOPSIS TRITHORAX1 dynamically regulates FLOWERING LOCUS C activation via histone 3 lysine 4 trimethylation. Plant Cell. 2008;20(3):580-588.

49. Berr A, Xu L, Gao J, Cognat V, Steinmetz A, Dong A, Shen WH. SET DOMAIN GROUP25 encodes a histone methyltransferase and is involved in FLOWERING LOCUS $\mathrm{C}$ activation and repression of flowering. Plant Physiol. 2009;151(3):1476-1485.

50. Berr A, Shafig S, Pinon V, Dong AW, Shen WH. The trxG family histone methyltransferase SET DOMAIN GROUP 26 promotes flowering via a distinctive genetic pathway. Plant J. 2015;81(2):316-28.

51. Liu B, Wei G, Shi JL, Jin J, Shen T, Ni T, Shen WH, Yu Y, Dong A. SET DOMAIN GROUP 708, a histone H3 lysine 36-specific methyltransferase, controls flowering time in rice (Oryze sativa). New Phytol. 2016;210(2):577-588.

52. Sun CH, Fang J, Zhao TL, Xu B, Zhang FT, Liu LC, Tang JY, Zhang GF, Deng XJ, Chen F, Qian Q, Cao XF, Chu CC. The histone methyltransferase SDG724 mediates H3K36me2/3 deposition at MADS50 and RFT1 and promotes flowering in rice. Plant Cell, 2012;24(8):3235-3247.

53. Sui PF, Shi JL, Cao XY, Shen WH, Dong A. H3K36 methylation is involved in promoting rice flowering. Mol Plant. 2013;6(3):975-7. 
54. Margueron R, Reinberg D. The Polycomb complex PRC2 and its mark in life. Nature. 2011;469(7330):343-349.

55. Shu J, Chen C, Thapa RK, Bian SM, Nguyen V, Yu KF, Yuan ZC, Liu J, Kohalmi SE, Li CL, Cui YH. Genomewide occupancy of histone H3K27 methyltransferases CURLY LEAF and SWINGER in Arabidopsis seedlings. Plant Direct. 2019;3(1):e00100.

56. Bouyer D, Roudier F, Heese M, Andersen ED, Gey D, Nowack MK, Goodrich J, Renou JP, Grini PE, Colot V, Schnittger A. Polycomb repressive complex 2 controls the embryo-to-seedling phase transition. PLoS Genet. 2011;7(3):e1002014.

57. He CS, Chen XF.; Huang H, Xu L. Reprogramming of H3K27me3 is critical for acquisition of pluripotency from cultured Arabidopsis tissues. PLoS Genet. 2012;8(8):e1002911.

58. Lafos M, Kroll P, Hohenstatt ML, Thorpe FL, Clarenz O, Schubert D. Dynamic regulation of H3K27 trimethylation during Arabidopsis differentiation. PLoS Genet. 2011;7(4):e1002040.

59. Lu FL, Cui X, Zhang SB, Jenuwein T, Cao XF. Arabidopsis REF6 is a histone H3 lysine 27 demethylase. Nat Genet. 2011;43(7):715-719.

60. Schubert D, Primavesi L, Bishopp A, Roberts G, Doonan J, Jenuwein T, Goodrich J. Silencing by plant Polycomb-group genes requires dispersed trimethylation of histone $\mathrm{H} 3$ at lysine 27. EMBO J. 2006;25(19):4638-4649.

61. Zheng BL, Chen XM. Dynamics of histone H3 lysine 27 trimethylation in plant development. Curr Opin Plant Biol. 2011;14(2):123-129.

62. Whitcomb SJ, Basu A, Allis CD, Bernstein E. Polycomb Group proteins: An evolutionary perspective. Trends Genet. 2007;23(10):494-502.

63. De Lucia F, Crevillen P, Jones AME, Greb T, Dean C. A PHD-polycomb repressive complex 2 triggers the epigenetic silencing of FLC during vernalization. Proc Natl Acad Sci U S A. 2008;105(44):16831-16836.

64. Jiang DH, Wang YQ, Wang YZ, He YH. Repression of FLOWERING LOCUS C and FLOWERING LOCUS T by the Arabidopsis polycomb repressive complex 2 components. PLoS One. 2008;3(10):e3404.

65. Lopez-Vernaza M, Yang SX, Müller R, Thorpe F, de Leau E, Goodrich J. Antagonistic roles of SEPALLATA3, FT and FLC genes as targets of the polycomb group gene CURLY LEAF. PLoS One. 2012;7(2):e307159.

66. Schönrock N, Bouveret R, Leroy O, Borghi L, Köhler C, Gruissem W, Hennig L. Polycomb-group proteins repress the floral activator AGL19 in the FLC-independent vernalization pathway. Genes Dev. 2006;20(12):1667-1678.

67. Wood CC, Robertson M, Tanner G, Peacock WJ, Dennis ES, Helliwell CA. The Arabidopsis thaliana vernalization response requires a polycomb-like protein complex that also includes VERNALIZATION INSENSITIVE 3. Proc Natl Acad Sci U S A. 2006;103(39):14631-14636.

68. Crevillén P, Yang H, Cui X, Greeff C, Trick M, Qiu Q, Cao XF, Dean C. Epigenetic reprogramming that prevents transgenerational inheritance of the vernalized state. Nature. 2014;515(7528):587-590.

69. Wu HW, Deng SL, Xu HY, Mao HZ, Liu J, Niu QW, Wang H, Chua NH. A noncoding RNA transcribed from the AGAMOUS (AG) second intron binds to CURLY LEAF and represses AG expression in leaves. New Phytol. 2018;219(4): 1480-1491. 
70. Payá-Milans M, Poza-Viejo L, Martín-Uriz PS, Lara-Astiaso D, Wilkinson MD, Crevillén P. Genome-wide analysis of the H3K27me3 epigenome and transcriptome in Brassica rapa. Gigascience. 2019;8(12):giz147.

71. Huang SN, Liu ZY, Li DY, Yao RP, Meng Q, Feng H. Screening of Chinese cabbage mutants produced by Co-60 gamma ray mutagenesis of isolated microspore cultures. Plant Breeding. 2014;133(4):480-488.

72. Fu W, Ye XL, Ren J, Li QQ, Du JT, Hou AL, Mei FB, Feng H, Liu ZY. Fine mapping of Icm1, a gene conferring chlorophyll-deficient golden leaf in Chinese cabbage (Brassica rapa ssp. pekinensis). Mol Breeding. 2019;39(4):52.

73. Wang N, Zhang Y, Huang SN, Liu ZY, Li CY, Feng H. Defect in Brnym1, a magnesium-dechelatase protein, causes a stay-green phenotype in an EMS-mutagenized Chinese cabbage (Brassica campestris L. ssp. pekinensis) line. Hortic Res. 2020;7:8.

74. Yu Y, Zhang FL, Zhao XY, Zhang DS, Zhang ZX. Rapid identification method of late bolting character in Chinese cabbage. China Vegetables. 2004;2004:16-18.

75. Abe A, Kosugi S, Yoshida K, Natsume S, Takagi H, Kanzaki H, Matsumura H, Yoshida K, Mitsuoka C, Tamiru M.; Innan H, Cano L, Kamoun S, Terauchi R. Genome sequencing reveals agronomically important loci in rice using MutMap. Nat Biotechnol. 2012;30(2):174-178.

76. Li H, Durbin R. Fast and accurate short read alignment with Burrows-Wheeler transform. Bioinformatics 2009;25(14):1754-1760.

77. Li H, Handsaker B, Wysoker A, Fennell T, Ruan J, Homer N, Marth G, Abecasis G, Durbin R. The sequence alignment/map format and SAMtools. Bioinformatics. 2009;25(16):2078-2079.

78. McKenna A, Hanna M, Banks E, Sivachenko A, Cibulskis K, Kernytaky A, Garimella K, Altshuler D, Gabriel S, Daly M, DePristo MA. The Genome Analysis Toolkit: a MapReduce framework for analyzing nextgeneration DNA sequencing data. Genome Res. 2010; 20(9):1297-1303.

79. Wang K, Li MY, Hakonarson H. ANNOVAR: functional annotation of genetic variants from highthroughput sequencing data. Nucleic Acids Res. 2010;38(16):e164.

80. Livak KJ, Schmittgen TD. Analysis of relative gene expression data using real-time quantitative PCR and the 2 (-Delta Delta C(T)) method. Methods. 2001;25(4):402-408.

81. Ji RQ, Ge WJ, Wang HM, Zhao Y, Feng H. BrSK13, a multiple-allele-inherited male sterility-related gene in Chinese cabbage (Brassica rapa L. ssp. pekinensis), affects pollen development and pollination/fertilization process. Gene. 2019;696:113-121.

82. Pertea M, Kim D, Pertea GM, Leek JT, Salzberg SL. Transcript-level expression analysis of RNA-Seq experiments with HISAT, StringTie, and Ballgown. Nat Protoc. 2016;11(9):1650-1667.

83. Ashburner M, Ball CA, Blake JA, Botstein D, Butler H, Cherry JM, Davis AP, Dolinshi K, Dwight SS, Eppig JT, Harris MA, Hill DP, Issel-Tarver L, Kasarskis A, Lewis S, Matese JC, Richardson JE, Ringwald M, Rubin GM, Sherlock G. Gene ontology: tool for the unification of biology. The gene ontology consortium. Nat Genet. 2000;25(1):25-29.

84. Kanehisa M, Araki M, Goto S, Hattori M, Hirakawa M, Itoh M, Katayama T, Kawashima S, Okuda S, Tokinatsu Y, Yamanishi Y. KEGG for linking genomes to life and the environment. Nucleic Acids Res 2008;36(Database issue):D480-454. 


\section{Figures}

A

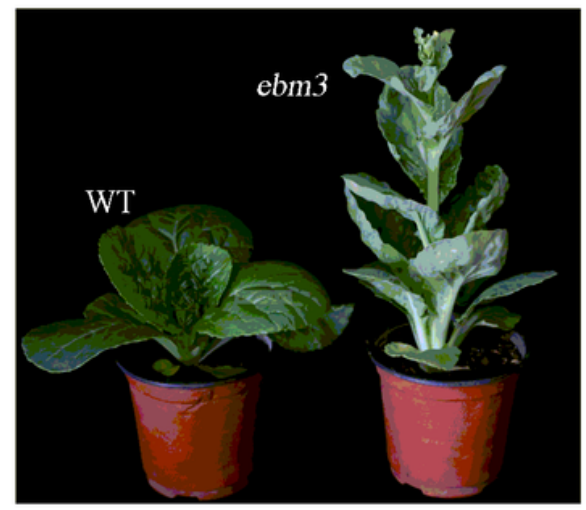

$\mathrm{C}$

WT

AICAGGITITACTIGGAATAICTGATGTAGCTGGITGGGGAGCITTCCTAAAGGTATAGTA

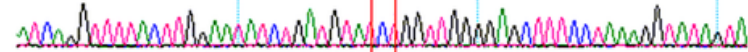
ATCAGGITITACTIGGAATATCIGATGIA_CIGGTTGGGGGCTITCCTAAAGGIATAGTA

ebm3
B

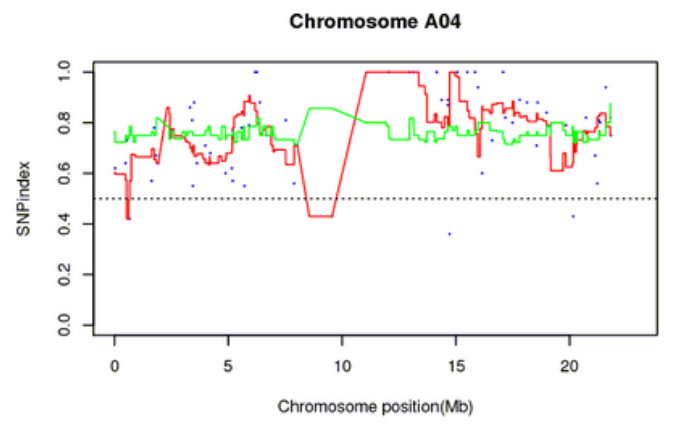

$\mathrm{D}$

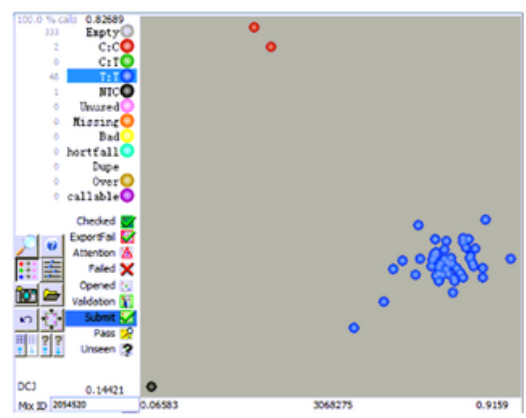

\section{Figure 1}

Identification of the mutant ebm3 and candidate SNPs. a Phenotypic characterization of the wild-type line 'FT' (left) and the mutant ebms3 (right). b The distribution of SNP index in offspring pool on chromosome A04 generated by MutMap analysis. b Sequencing peak of the C/T allele of SNP 13,129,878 generated by Sanger sequencing. d KASP genotyping results of SNP 13,129,878 in F2 individuals. 
A

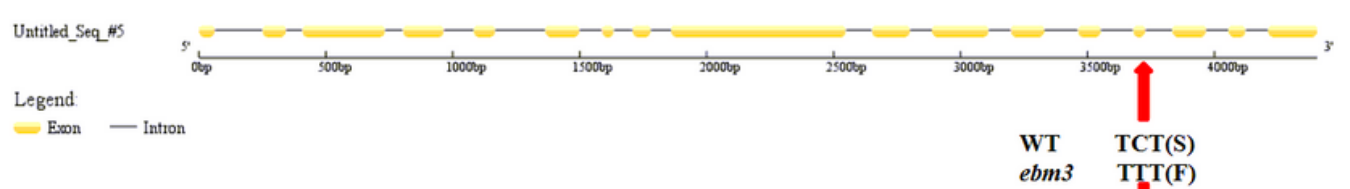

B

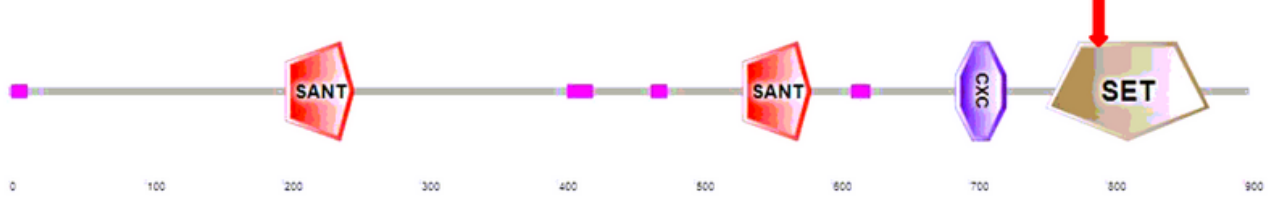

$\mathrm{C}$

ebm3_Brassica rapa WT_Brassica rapa

AaCLF_Arabis alpina
AtCLF_Arabidpsis thaliana

AtCLF_Arabidpsis thaliana

GaCLF_Gossypium arboreu

MdCLF_Malus domestica
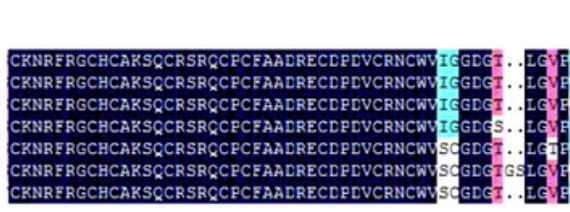

\section{Figure 2}

Sequence analysis of the causal gene, Brebm3. a Gene structure of the causal gene Brebm3 and the site of nonsynonymous base substitution. b Conserved domain analysis of Brebm3 and the site of amino acid change. c Sequence alignment of CLF in various species. The CLF protein accession numbers are follows: Arabis alpina, AaCLF (KFK32747.1); Arabidopsis thaliana, AtCLF (CAA71599.1); Populus trichocarpa, PtCLF (XP_024460754.1); Gossypium arboreum, GaCLF (KHG06300.1); Malus domestica, MdCLF (XP_008340296.2). 
A

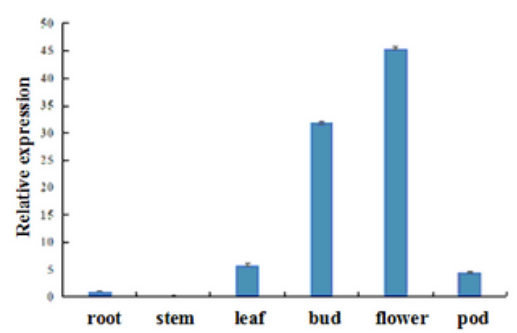

$\mathrm{B}$

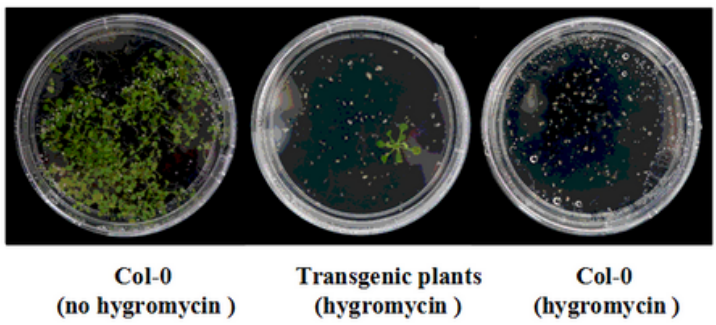

C

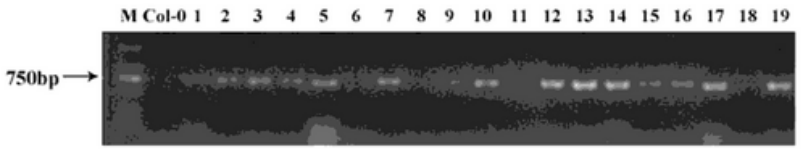

$\mathrm{D}$

$$
\text { Col-0 (no vector) Brebm3 pro:GUS }
$$

roo
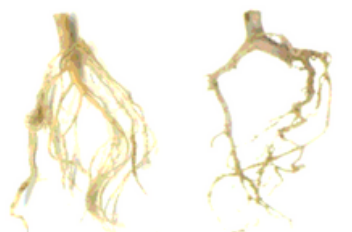

stem
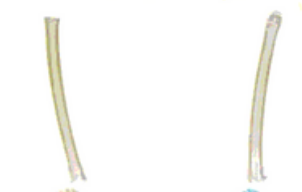

leaf

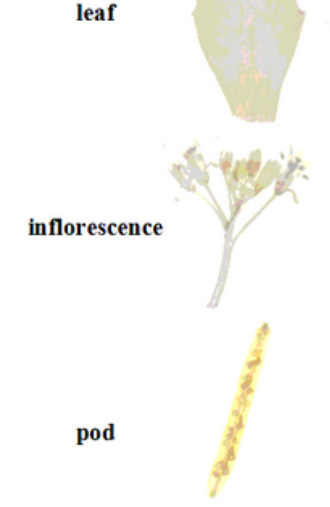

\section{Figure 3}

Expression pattern analysis of the causal gene Brebm3. a Spatiotemporal expression of Brebm3 in the wildtype line 'FT'. b Screening of hygromycin-resistant transgenic plants on MS medium. c PCR-based DNA genotyping of transgenic plants using the GUS reporter gene. d GUS staining of homozygous T2-generation transgenic plants. 


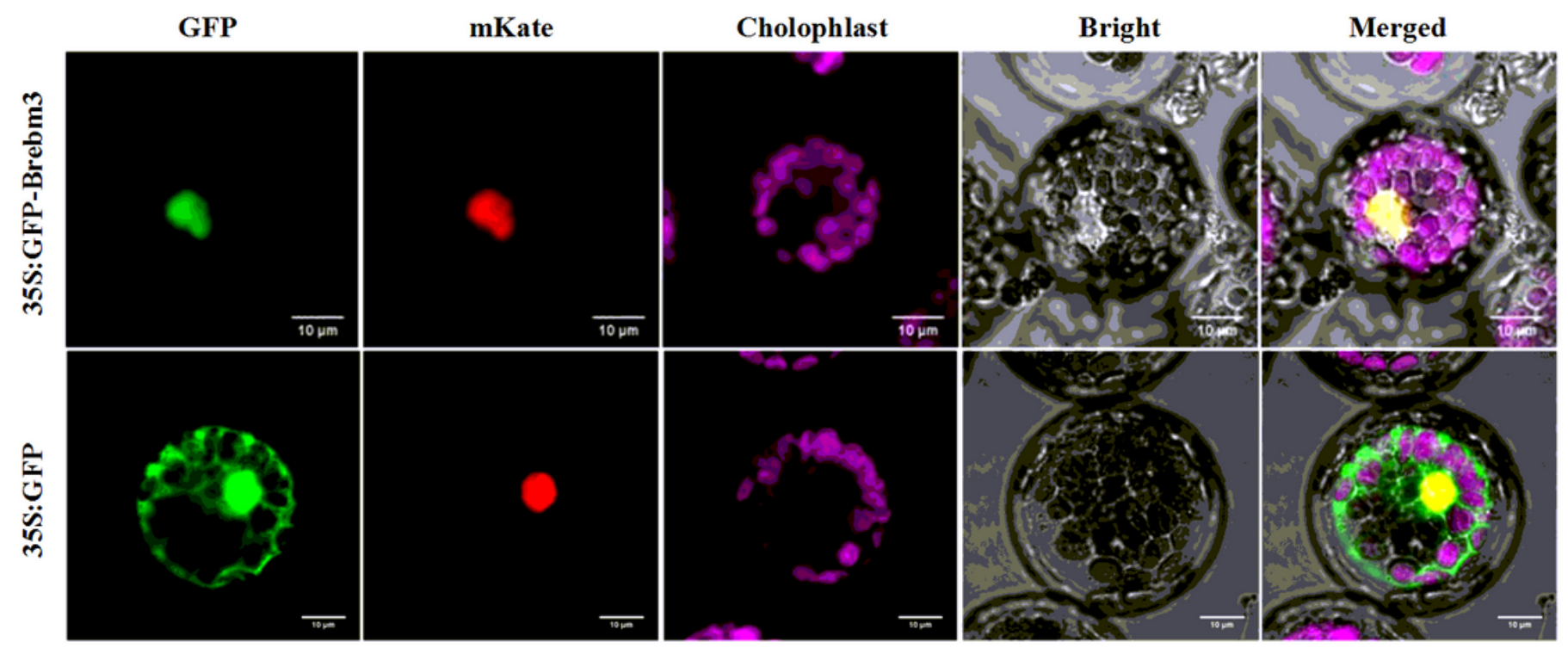

\section{Figure 4}

Subcellular localization analysis of Brebm3. The 35S:GFP-Brebm3 and blank 35S:GFP vectors were transiently expressed in Arabidopsis mesophyll cell protoplasts. The nuclear localization signal (NLS) protein fused with mKate was used as a nucleus marker. Confocal images were captured 24-48h after inoculation and observed under a confocal laser-scanning microscope. The merged images include GFP channel (green), mKate channel (red), chloroplast autofluorescence channel (pink) and bright field. Scale bar, $10 \mu \mathrm{m}$.

A

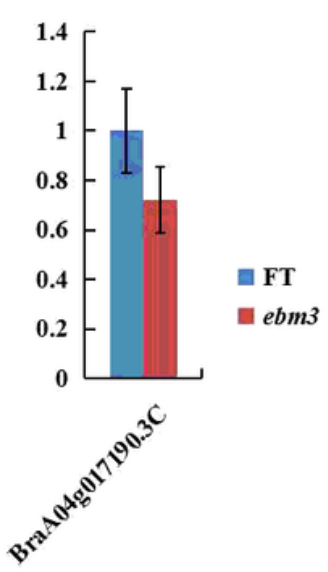

B

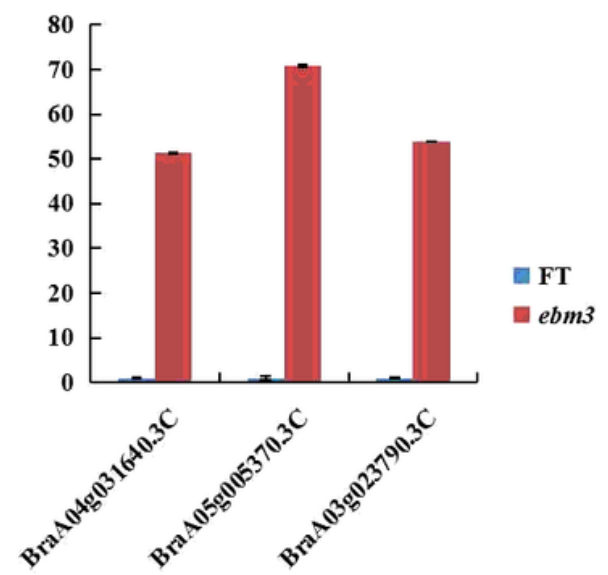

$\mathrm{C}$

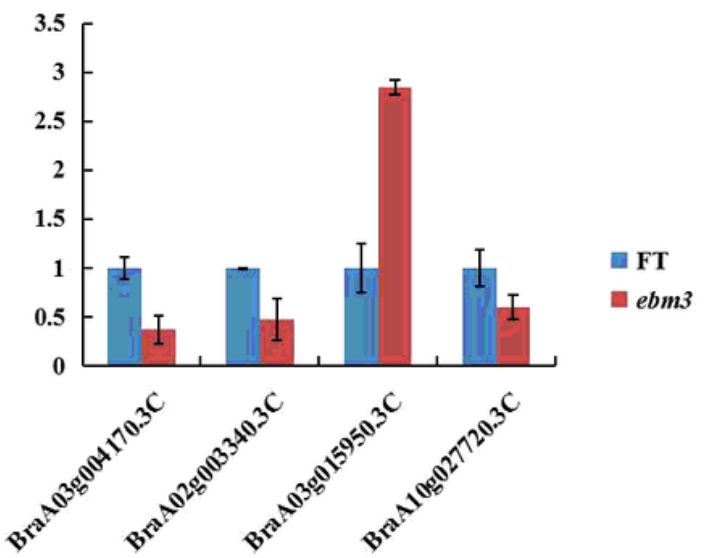

\section{Figure 5}

Expression analysis of genes associated with flowering time regulation in the SAM of the mutant ebm3 and wild-type line 'FT'. a Analysis of Brebm3 expression; b Analysis of SOC1 expression. c Analysis of FLC expression.

\section{Supplementary Files}

This is a list of supplementary files associated with this preprint. Click to download. 
- Additionalfile1.docx

- Additionalfile2.docx

- FigureS1.jpg

- FigureS2.jpg 